\title{
Physicochemical, microbial and sensory changes of minimally processed durian (Durio zibethinus cv. D24) during storage at 4 and $28{ }^{\circ} \mathrm{C}$.
}

\begin{abstract}
The effect of storage temperature on physicochemical, microbial and sensory quality of minimally processed durian (Durio zibethinus Murray) was determined at $28{ }^{\circ} \mathrm{C}$ for 3 days and $4{ }^{\circ} \mathrm{C}$ for 35 days. When held at $28{ }^{\circ} \mathrm{C}$, the pulp retained its colour but softened rapidly after $24 \mathrm{~h}$ and became acidic ( $\mathrm{pH} 4.71)$ after 2 days of storage due to the formation of citric, succinic, acetic and lactic acids. Sucrose decreased concomitantly with increase in glucose and fructose contents during storage. For fruit stored at $4{ }^{\circ} \mathrm{C}$, no noticeable changes in $\mathrm{pH}$ occurred. Following 1 week of storage, there was a progressive increase in glucose, fructose and sucrose contents concomitant with the increase in total soluble solids. The firmness increased significantly $(\mathrm{P}<0.05)$ at the end of storage. The organic acid content remained constant throughout storage with a minor increase in tartaric acid detected. Titratable acidity of the fruit correlated well with the shift in organic acid profile instead of $\mathrm{pH}$. Sensory evaluation revealed off-odour development on day 14 for fruit stored at $4{ }^{\circ} \mathrm{C}$. The off-flavour increased to an unacceptable point on day 28 of storage. The minimally processed durian fruit could be held at $4{ }^{\circ} \mathrm{C}$ for 14 days with acceptable microbiological count and without offodour development. At ambient temperature, minimally processed durian could only be stored for 1 day after which the pulp became acidified.
\end{abstract}

Keyword: Durian, Minimally processed, Ambient temperature, Chilled temperature 